\title{
Vascularized Bone Grafting for Scaphoid Nonunion with Humpback Deformity: The Surgical Technique
}

\author{
Keikichi Kawasaki, MD, PhD ${ }^{1}$ Tetsuya Nemoto, MD, PhD ${ }^{1}$ Kazutoshi Kubo, MD, PhD ${ }^{1}$ \\ Kazunari Tomita, $\mathrm{MD}, \mathrm{PhD}^{1}$ Katsunori Inagaki, $\mathrm{MD}, \mathrm{PhD}^{1}$ \\ ${ }^{1}$ Department of Orthopedic Surgery, Showa University, School of \\ Medicine, Tokyo, Japan \\ J Wrist Surg 2020;9:528-534. \\ Address for correspondence Tetsuya Nemoto, MD, PhD, Department \\ of Orthopedic Surgery, Showa University, School of Medicine, \\ Hatanodai 1-5-8, Shinagawa-ku, Tokyo 142-8555, Japan \\ (e-mail: t-nemoto@grad.showa-u.ac.jp).
}

Abstract

Keywords
- scaphoid nonunion
- vascularized bone
graft
- humpback deformity
- direct lateral
approach
- radial approach

Background Scaphoid nonunion with humpback deformity and avascular necrosis $(A V N)$ is a challenging problem. Correction of dorsal intercalated segment instability (DISI) requires grafting of a large and hard vascularized bone segment onto the volar side of the scaphoid.

Purposes We have been treating the patients with one-incision vascularized bone grafting technique for scaphoid nonunion to improve blood supply and correct humpback deformity. We evaluated these cases retrospectively to the surgical efficacy of our procedure.

Methods We harvested vascularized bone from the dorsal side of the radius using the method by Zaidemberg et al and inserted the cortical aspect into the scaphoid volar side using a direct lateral approach. Totally, 11 patients (nine males andtwo females) with a mean age of 40 years were recruited for this study. The mean time from fracture to treatment was 6 years and 3 months. The mean preoperative radiolunate angle was 25 degrees. All the patients showed AVN of the proximal scaphoid on T1-weighted images. An averaged follow-up period was 2 years and 3 months.

Results Postoperative computed tomography revealed bony union in 10 patients (91\% of union rate) with a mean modified Mayo'swrist score of 88 points (range, 75-100 points) and a mean disabilities of arm, shoulder, and hand (DASH) score of 4 points (range, $0-20$ points). The mean radiolunate angle was corrected from 25 to 5 degrees. No adverse events were observed, except temporary mild paresthesia of the radial nerve territory in two patients.

Conclusion This technique effectively corrected DISI in patients with scaphoid nonunion accompanied by humpback deformity and AVN.
Bone grafting for scaphoid nonunion is performed using multiple techniques. Matti first reported grafting of bone onto the scaphoid dorsal side in $1936^{1}$ and Russe later described a technique involving the volar side. ${ }^{2}$ In 1970 , Fisk suggested the use of a conventional wedge graft to correct scaphoid length. ${ }^{3}$

received

November 11, 2019

accepted

July 6, 2020

published online

September 3, 2020
In 1991, Zaidemberg et al reported a technique for vascularized bone grafting based on the ascending irrigating branch of the radial artery. ${ }^{4}$ In cases of scaphoid nonunion with avascular necrosis (AVN), such vascularized bone grafts may provide better results. Makino reported on the harvesting of vascularized bone from the dorsal base of the second

Copyright @ 2020 by Thieme Medical Publishers, Inc., 333 Seventh Avenue, New York, NY 10001, USA. Tel: +1(212) 760-0888.
DOI https://doi.org/ 10.1055/s-0040-1715800. ISSN 2163-3916. 
metacarpal bone, ${ }^{5}$ and subsequent reports have described treatments that involve harvesting vascularized bone from the volar aspect of the radius, ${ }^{6}$ the first metacarpal bone, ${ }^{7}$ or the head of the second metacarpal bone. ${ }^{8}$

Chang et al used the bone harvesting technique by Zaidemberg et al to treat a scaphoid nonunion with humpback deformity and AVN; however, the results were not satisfactory. ${ }^{9}$ Fisk proposed that scaphoid nonunion with humpback deformity and AVN requires grafting of a large section of hard iliacbone onto the volar side to avoid loss of correction. ${ }^{3}$ It is easier to isolate and preserve the vascular pedicle while transferring the graft from the dorsal side to the volar side using Makino's technique compared with the technique by Zaidemberg et al. However, with Makino's technique it is more difficult to harvest a large bone.

We believe, the harvesting of a large section of hard grafting vascularized bone is essential for optimal correction. Waitayawinyuetal reported one-incision radial approach technique with a radial stylodectomy to access the radial aspect of scaphoid and transfer vascularized graft of dorsal radius pedicled with 1,2 intercompartmental supraretinacular artery (1,2-ICSRA); however, the technique was not well described in detail. ${ }^{10}$ Original method by Zaidemberg et al was difficult to graft on radial or volar side of scaphoid. It is necessary to remove radial styloid to access radial aspect of scaphoid and transfer vascularized bone graft (VBG) from dorsal side of distal radius to volar side of scaphoid. Our method involves harvesting a vascularized bone graft from the dorsal radius, followed by insertion of the cortical aspect into the volar side of the scaphoid. This technique also helps create a safe pathway for the pedicle to achieve stable bony union. Since 2011, we have treated 11 cases of scaphoid nonunion with humpback deformity and AVN using this technique. This study retrospectively evaluates the clinical and radiological results of these cases to clarify the surgical efficacy of this procedure.

\section{Materials and Methods}

Between 2011 and 2015, we indicated this technique for all scaphoid nonunion with humpback deformity. The definition of scaphoid nonunion was the duration of scaphoid nonunion longer than 6 weeks. Humpback deformity with radiolunate (RL) angle more than 10 degreeswas included in this study. Nonunion was confirmed by an absence of fragment continuity using preoperative plain radiographs and computed tomography (CT). Preoperative scaphoid nonunion advanced collapse (SNAC wrist) stages 2 and 3 were excluded. Patients who have been performed operation for scaphoid was excluded. We evaluated the bony union and RL angle according to radiological outcomes, range of motion (ROM; volar flexion and dorsiflexion), grip strength ratio of injured side to uninjured side, the modified Mayo wrist score(MMWS), disabilities of arm, shoulder, and hand (DASH) score, and complication rates. In addition, we recorded the size of the grafted bone (-Table 1). Bone union was assessed by CT. Axial, coronal, and sagittal view were reconstructed for each case and bone union was confirmed by bridging callus or heal of gap in more than two dimensions. CT was assessed by surgeon.

\section{Surgical Techniques}

A curvilinear incision was made over the first and second retinacular compartments proximal to the scaphoid process (-Figs. 1A and 2A) to open the compartments longitudinally. To access volar side of scaphoid, distal edge of incision was made on volar side compared with original method by Zaidemberg et al. The bone graft was harvested through the floor of these two compartments, taking care to maintain the vascular supply of the 1,2-ICSRA (-Fig. 2B). We harvested approximately $10 \mathrm{~mm} \times 10 \mathrm{~mm} \times 15 \mathrm{~mm}$ of corticocancellous bone from the distal radius using a sagittal saw, as proposed by Zaidemberg et al (-Fig. 2C). ${ }^{4}$

The distal edge of the pedicle was dissected and lifted with the periosteum of the tip of the radial styloid. After the graft was harvested, we detached the joint capsule, from the styloid to the volar side $(5-10 \mathrm{~mm}$ from the tip), and the resected the tip of radial styloid to create an intraoperative view of the lateral and volar radial side of the scaphoid. After retracting part of the scaphoid nonunion to the volar side by turning the pedicled vascularized bone, we cleaned the edges of the nonunion by removing any fibrous tissue, particularly on the volar side of the scaphoid bone (- Figs. 1B and 2D). We used Tomaino's ${ }^{11}$ technique to reduce the dorsal intercalated segment instability (DISI) deformity. ${ }^{10}$

Briefly, the wrist was flexed laterally under fluoroscopic imaging until a neutral RL angle was obtained. Then, we fixed the lunate in this reduced position using the Kirschner wire. Kirschner's wire was inserted from dorsal radius to lunate across RL joint. We measured the size of the bone defect, shaped the harvested bone appropriately, and inserted it with the cortical aspect turned toward the volar side of the scaphoid (-Figs. 1B and 2E). The graft was fixed using a retrograde or antegrade cannulated headless screw (DTJ screw,Meira, Nagoya, Japan) with Kirschner's wire added temporarily (percutaneously) parallel to the screw into the wound. The Kirshner wire on the RL joint was removed. The wrist was immobilized in a short-arm thumbspica splint for 6 weeks, after which we removed the splint and the patient began exercises to increase ROM. After bone union was confirmed, the Kirschner wire parallel to the screw was removed.

\section{Results}

Between 2011 and 2015, 11 patients of scaphoid nonunion with humpback deformity and AVN were treated with our technique. The mean age of the patients was 40 years (range, 17-70 years) and the dominant wrist was affected in five of these patients. The mean interval from fracture to vascularized bone grafting was 6 years and 3 months (range, 5 months-30 years). Patients were followed-up postoperatively for an average of 2 years 3 months (range, 1-5 years). No patients underwent prior surgeries for the correction of scaphoid nonunion. The nonunion was located at the scaphoid waist in 10 patients and at the distal part in 1 patient. The mean preoperative RL angle was 25 degrees (range, 12-54 degrees). There were five patients with preoperative SNAC wrist stage 1 . All the patients were examined using noncontrast magnetic resonance imaging (MRI) that revealed 
Table 1 Clinical data for all 11 patients

\begin{tabular}{|c|c|c|c|c|c|c|c|c|c|c|c|c|c|}
\hline \multicolumn{2}{|l|}{ Number } & 1 & 2 & 3 & 4 & 5 & 6 & 7 & 8 & 9 & 10 & 11 & Ave. \\
\hline \multicolumn{2}{|l|}{ Age (y) } & 17 & 18 & 20 & 29 & 31 & 32 & 49 & 50 & 59 & 68 & 70 & 40 \\
\hline \multicolumn{2}{|c|}{ Sex/affected hand } & $\mathrm{M} / \mathrm{L}$ & $M / R$ & $M / R$ & $M / R$ & $\mathrm{M} / \mathrm{L}$ & $\mathrm{M} / \mathrm{L}$ & $M / R$ & $F / R$ & $\mathrm{M} / \mathrm{L}$ & $\mathrm{M} / \mathrm{L}$ & $\mathrm{F} / \mathrm{L}$ & \\
\hline \multicolumn{2}{|c|}{ Nonunion duration } & $8 \mathrm{mo}$ & $5 \mathrm{mo}$ & $1 \mathrm{y}$ & $2 y$ & $\begin{array}{l}1 \text { y } 3 \\
\text { mo }\end{array}$ & $3 \mathrm{mo}$ & $\begin{array}{l}2 \text { y } 3 \\
\text { mo }\end{array}$ & $30 y$ & $8 \mathrm{mo}$ & $30 y$ & $7 \mathrm{mo}$ & 6 y $3 \mathrm{mo}$ \\
\hline \multicolumn{2}{|c|}{$\begin{array}{l}\text { Postoperative } \\
\text { follow-up period }\end{array}$} & $1 \mathrm{y}$ & $5 y$ & $1 \mathrm{y}$ & 3 y $7 \mathrm{mo}$ & $1 \mathrm{y}$ & $1 \mathrm{y}$ & $1 \mathrm{y}$ & $1 \mathrm{y}$ & 3 y $7 \mathrm{mo}$ & 2 y $6 \mathrm{mo}$ & $2 y$ & 2 y $3 \mathrm{mo}$ \\
\hline \multicolumn{2}{|c|}{ Herbert classification } & D2 & D2 & D3 & D3 & D2 & D2 & D3 & D3 & $\mathrm{D} 2$ & D3 & D2 & - \\
\hline \multirow[t]{2}{*}{ MRI of pre-op } & $\mathrm{T} 1$ & Low & Low & Low & Low & Low & Low & Low & Low & Low & Low & Low & - \\
\hline & $\mathrm{T} 2$ & Iso & Iso & Low & High & Iso & Iso & Iso & Low & High & Low & Low & - \\
\hline \multicolumn{2}{|c|}{ Part of nonunion } & Mid & Mid & Mid & Dist & Mid & Mid & Mid & Mid & Mid & Mid & Mid & - \\
\hline \multicolumn{2}{|l|}{$\begin{array}{l}\text { Area of grafted } \\
\text { bone }\left(\mathrm{cm}^{2}\right)\end{array}$} & 81 & 48 & 81 & 80 & 54 & 81 & 80 & 180 & 81 & 64 & 70 & 82 \\
\hline \multirow{2}{*}{$\begin{array}{l}\text { Preoperative } \\
\text { ROM (degree) }\end{array}$} & $\mathrm{VF}$ & 45 & 20 & 70 & 70 & 80 & 85 & 65 & 90 & 40 & $\mathrm{~N} / \mathrm{A}$ & 55 & 62 \\
\hline & $\mathrm{DF}$ & 75 & 65 & 70 & 45 & 80 & 85 & 60 & 90 & 60 & $\mathrm{~N} / \mathrm{A}$ & 45 & 68 \\
\hline \multirow{2}{*}{$\begin{array}{l}\text { Postoperati- } \\
\text { veROM } \\
\text { (degree) }\end{array}$} & VF & 80 & 60 & 60 & 80 & 70 & 60 & 60 & 40 & 35 & 55 & 60 & 60 \\
\hline & DF & 80 & 80 & 70 & 80 & 90 & 60 & 70 & 60 & 60 & 45 & 70 & 70 \\
\hline \multicolumn{2}{|c|}{$\begin{array}{l}\text { Preoperative grip } \\
\text { strength ratio (\%) }\end{array}$} & 100 & $\mathrm{~N} / \mathrm{A}$ & 86 & $\mathrm{~N} / \mathrm{A}$ & 78 & 100 & 86 & 67 & 58 & 122 & 86 & 87 \\
\hline \multicolumn{2}{|c|}{$\begin{array}{l}\text { Postoperative grip } \\
\text { strength ratio (\%) }\end{array}$} & 96 & 98 & 110 & 106 & 88 & 81 & 69 & 80 & 116 & 82 & 96 & 93 \\
\hline \multicolumn{2}{|c|}{ The Mayo wrist score } & 90 & 90 & 90 & 95 & 90 & 90 & 80 & 80 & 90 & 75 & 90 & 87 \\
\hline \multicolumn{2}{|l|}{ DASH score } & 11 & 1 & 1 & 1 & 0 & 2 & 20 & 5 & 0 & 2 & 0 & 4 \\
\hline \multirow{3}{*}{$\begin{array}{l}\text { RL angle } \\
\text { (degree) }\end{array}$} & Pre-op & 15 & 33 & 21 & 54 & 21 & 15 & 15 & 35 & 24 & 12 & 27 & 25 \\
\hline & Post-op & 2 & 13 & 6 & 0 & 5 & 0 & 5 & 20 & 5 & 6 & 10 & 5 \\
\hline & RL angle & 13 & 20 & 15 & 54 & 16 & 15 & 10 & 15 & 19 & 6 & 17 & 20 \\
\hline \multirow{2}{*}{$\begin{array}{l}\text { SNAC wrist } \\
\text { stage }\end{array}$} & Pre-op & 0 & 0 & 0 & 0 & 0 & 0 & 1 & 1 & 1 & 1 & 1 & - \\
\hline & Post-op & 1 & 1 & 1 & 1 & 0 & 0 & 1 & 1 & 1 & 2 & 1 & - \\
\hline \multicolumn{2}{|l|}{ Union } & $\circ$ & $\circ$ & $\circ$ & $\circ$ & $\circ$ & $\circ$ & $\circ$ & $\circ$ & $\circ$ & $\mathrm{x}$ & $\circ$ & - \\
\hline
\end{tabular}

Abbreviations: Ave., average; DASH, disabilities of arm, shoulder and hand; DF, dorsal flexion; Dist, distal; F, female; L, left; M, male;Mid, medial; MRI, magnetic resonance imaging; N/A, not available (no data in medical record) ; Post-op, postoperative; Pre-op, preoperative; R, right; RL, radiolunate; ROM, range of motion; SNAC, scaphoid nonunion advanced collapse; VF, volar flexion.

proximal scaphoid AVN as indicated by low signal intensity on T1-weighted images (T1-MRI). Further, four patients also had low-signal intensity on T2-MRI.

- Table 1 presents detailed clinical profiles of the 11 patients. Postoperative CT revealed bony union in 10 patients. Postoperatively, there were eight patients with stage- 1 SNAC and 1 patient with stage-2 SNAC. The mean postoperative RL angle was 5 degrees (0-20 degrees) and the mean RL angle was corrected by 19 degrees.

All patients reported reduced or resolved pain and all resumed normal work following surgery. The mean preoperative/postoperative range of motion was 62 degrees (range, 20-90 degrees)/60 degrees (range, 35-80 degrees) in volar flexion (VF) and 68 degrees (range, 45-90 degrees)/ 70 degrees (range, 45-90 degrees) in dorsiflexion(DF;VF: $p=0.861$, DF: $p=0.496$ ). On the injured side, preoperative/ postoperative mean grip strength was $87 \%$ (range, $58-122 \%$ )/ 93\% (range, $69-116 \%$ ) of the uninjured side $(p=1.000)$. Postoperative ROM and grip power ratio did not differ from preoperative status $(p>0.05)$. The average postoperative MMWS was 87 points (range, 75-95 points). According to the category of MMWS, eight patients achieved excellent results, twoachieved good results, and one fair result. The average DASH score was 4 points (range, 0-20 points).

The mean size of the harvested bone (length $\times$ width) was $82 \mathrm{~mm}^{2}$ (range, $48-180 \mathrm{~mm}^{2}$ ). All the patients required excision of the radial styloid process. The only notable complication was temporary mild paresthesia of the superficial branch of the radial nerve area in two patients. No pin site infection was occurred.

\section{Sample Case}

A 32-year-old male injured her left hand while traffic accident 2 months earlier. He had scaphoid waist nonunion with a RL angle of 15 degrees, and the bone showed low intensity on T1-weighted image and iso intensity on T2-STIR (short TI inversion recovery) weighted images, indicative of AVN (-Fig. 3). The intraoperative findings were shown in -Fig. 2 (-Fig. 2). Bone union was confirmed at postoperative 3 months. He reported no pain, her MMWS was excellent at postoperative 1 year. The postoperative RL angle was 0 degrees (-Fig. 4). 
(A)
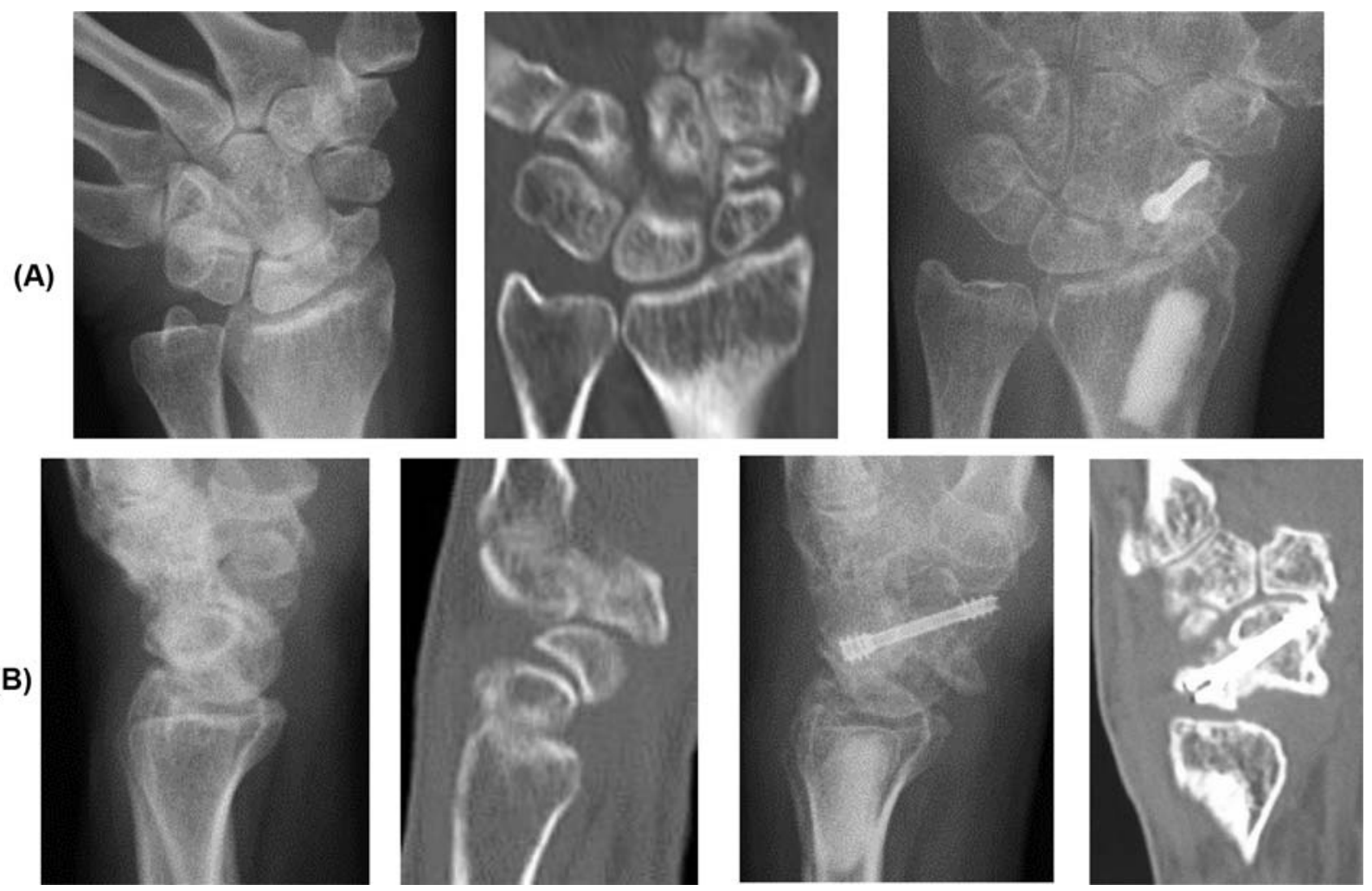

Fig. 1 Schema of our technique. (A) Curved skin incision on the radial side of the wrist. We elevated the harvesting bone pedicled from the 1,2 intercompartmental supraretinacular artery and detached the joint capsule from the styloid to the volar side. (B) We cut the tip of the radial styloid, excised the volar part of the scaphoid nonunion, and inserted harvested vascularized bone by rotating the cortical aspect of bone to the volar side.
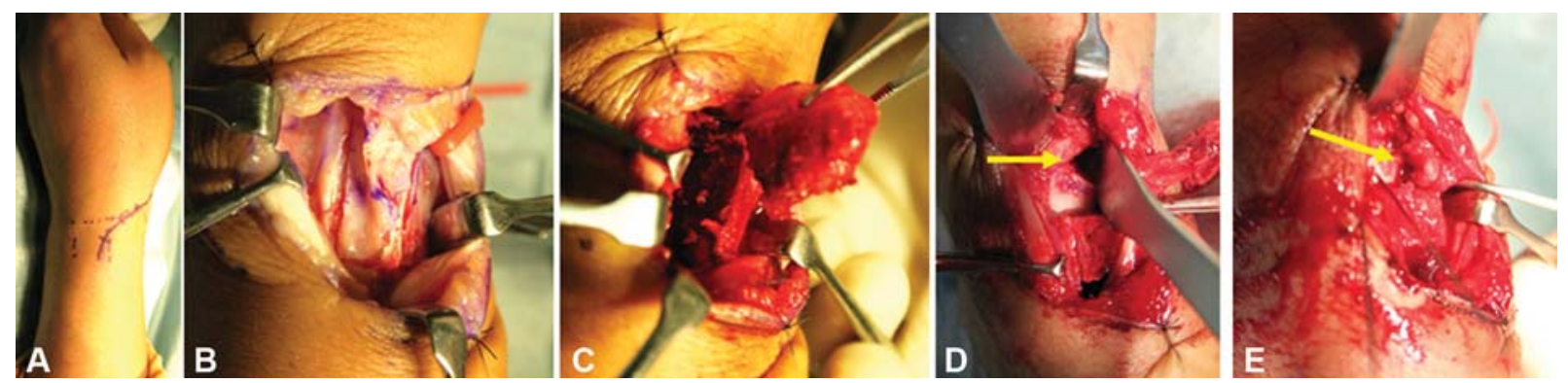

Fig. 2 intraoperative findings. (A) Skin incision. (B) Identified 1,2-ICSRA. (C) Turning the pedicled bone after harvesting. (D) Creating cavity on the scaphoid (arrow) (E) Inserting the vascularized bone onto the volar side. An arrow indicated pedicle. ICSRA, intercompartmental supraretinacular artery.

\section{Discussion}

In total, 11 patients of scaphoid nonunion with humpback deformity and AVN were treated with our vascularized bone grafting technique which uses only one incision. In radiological evaluation, 10 patients showed bony union and the mean $\mathrm{RL}$ angle was corrected from 25 to 5 degrees. The clinical evaluation of MMWS and DASH score gave fairly good results. Our problem was the need for vascularized bone graft for scaphoid nonunion with humpback deformity and AVN, and the usefulness of single-incision lateral approach.

Historical systematic review of studies on scaphoid nonunion, including 47 publications between 1928 and 2003 including 5,246 cases of scaphoid nonunion, found an aver- age union rate of $78 \%$ for proximal pole scaphoid nonunions, including those with AVN, when treated with nonvascularized bone grafting techniques. ${ }^{12}$ Recent systematic review between 1999 and 2014 showed improvement of bone union ratio; that of vascularized and nonvascularized bone graftings were 92 and $88 \%$, respectively. ${ }^{13}$ Even for case with AVN, the bone union ratio of VBG from distal radius for 78 cases was $96 \%{ }^{13}$ Individual studies have reported bony union rates of 60 to $95 \%$ for conventional bone grafting of scaphoid nonunion defects. ${ }^{14-19}$ Some of these studies report various treatment challenges associated with AVN, including patients with failed past operations, displaced bones, proximal pole nonunions, and patients with long nonunion times. For recalcitrant scaphoid nonunion, pedicled bone grafting 

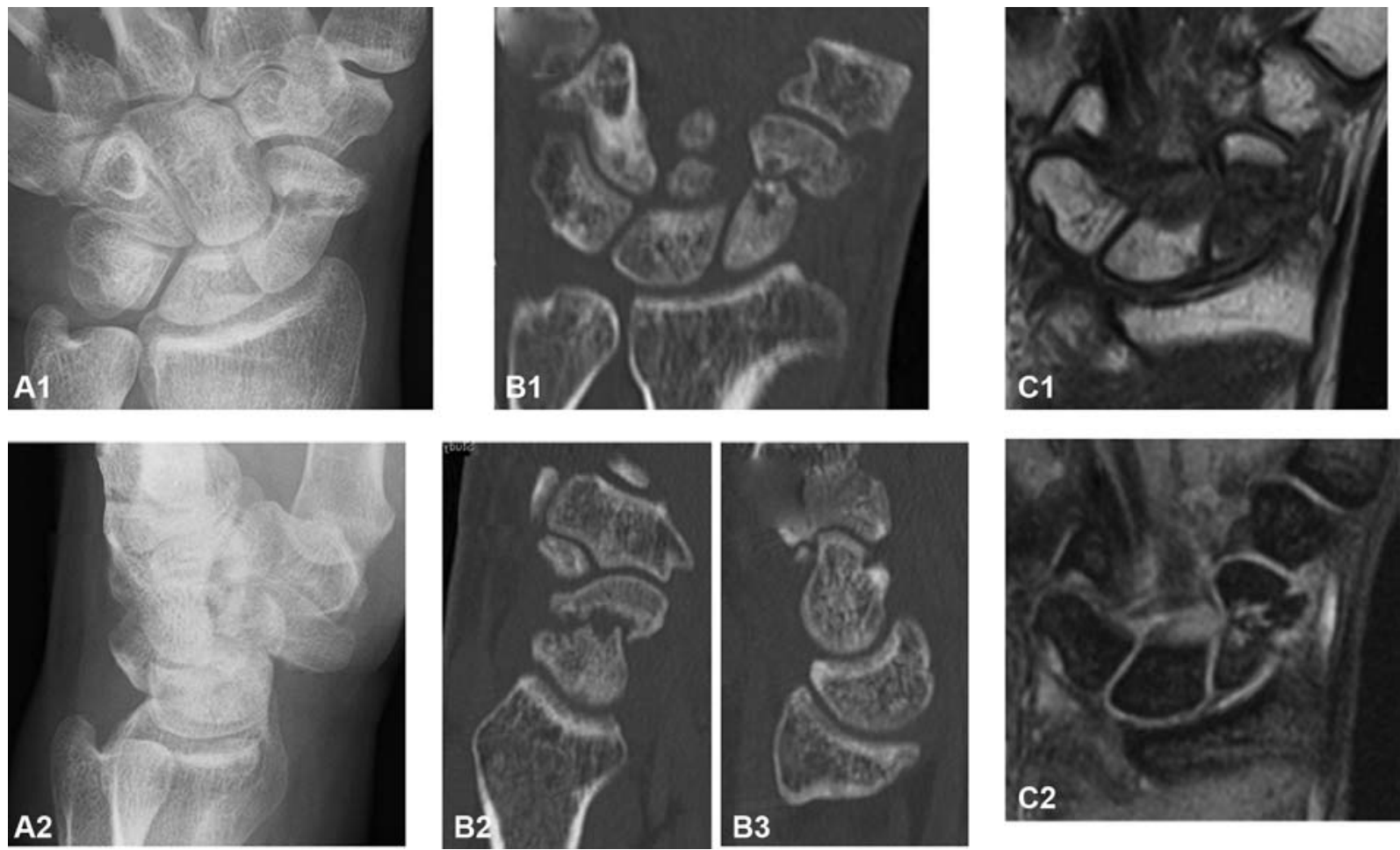

Fig. 3 Preoperative images. (A1) Preoperative anterolateral radiograph. (A2) Preoperative lateral radiograph. Preoperative CT scan:(B1)coronal, (B2) sagittal on the scaphoid, and (B3) sagittal on the lunate. (C1) Preoperative T1-weighted magnetic resonance imaging. (C2)Preoperative T2STIR image postoperative. CT, computed tomography. STIR, short TI inversion recovery.

has proven effective, and includes harvesting from the dorsal part of the distal radius as proposed by Zaidemberg et $\mathrm{al}^{4}{ }^{4}$ or the dorsal base of the second metacarpal bone as proposed by Makino. ${ }^{5}$ Ribak et al reported a higher bone union rate with a technique that used vascularized radial bone, compared with one that used nonvascularized radial bone $(89.1$ vs. $72.5 \%) .{ }^{20}$ They also reported superior clinical scores $(72.0$ vs. $57.5 \%){ }^{20}$ Thus, vascularized bone grafts are recommended for the treatment of scaphoid nonunion associated with AVN.

Successful surgical treatment of scaphoid nonunion and $\mathrm{AVN}$ is limited when a humpback deformity is present. For example, Megerle et al reported poorer results in patients with RL angles $>10$ degrees. ${ }^{21}$ Fisk suggested the use of a conventional wedge graft to correct scaphoid length, ${ }^{3}$ and Fernandez described a modified wedge graft technique for these patients. ${ }^{22}$ Sawaizumi et al ${ }^{23}$ harvested vascularized bone from the dorsal base of the second metacarpal bone using Makino's technique ${ }^{24}$ and reported better correction of the RL angle, a higher bone union rate (100\%), and greater Cooney's clinical score (mean: 82.1 points) after grafting to the volar side. Correction of scaphoid nonunion with humpback deformity requires a large section of hard bone for grafting onto the volar side, especially in case of waist nonunion with humpback deformity. Makino's technique allows for easy insertion because the pedicle artery is wide; however, the dorsal base of the second metacarpal bone is much smaller than the dorsal aspect of the distal radius. Thus, harvesting a large bone section is more difficult. To circumvent this problem, we harvested the graft bone from the dorsal aspect of the distal radius, like the technique of Zaidemberg et al, but we used the direct lateral approach to reduce the risk of pedicle damage. Although original method by Zaidemberg et al used Kirschner wire to fix VBG, we used headless compression screw for internal fixation because we think it is important to compress large hard VBG on fracture site by headless compression screw. Bone union ratio reported on systematic review was $92 \%$ by Kirschner wire fixation and $88 \%$ by screw fixation. ${ }^{13}$

Tambe et al reported 11 patients treated with vascularized bone grafts from the dorsum of the distal radius. ${ }^{24}$ However, correction of the humpback deformity using a single dorsal approach was not possible and the overall union rate was only $55 \%(6 / 11)$. It is possible that their low success rate for bone grafts vascularized from the 1,2 ICSRA was due to palmar rotation, which may "kink" the pedicle during insertion. Alternatively, a scaphoid nonunion with substantial bone loss and a humpback deformity may not heal when the method by Zaidemberg et al is used. Arora et al obtained bony union in 16 of 21 patients with partial correction of palmar rotation of the scaphoid and DISI deformity using free vascularized iliac crest bone grafts. ${ }^{25}$ Jones et al found that the union rate of the proximal scaphoid fragment in patients with wrist nonunion and collapse was much lower when the method by Zaidemberg et al was used (40\%) than a free vascularized bone graft method (100\%). ${ }^{26}$ Collectively, these reports suggest limited success using a pedicled vascularized bone graft. While the method by Zaidemberg et al allows for easy harvesting of a large bone section, the pedicle artery is narrow, increasing the risk of 

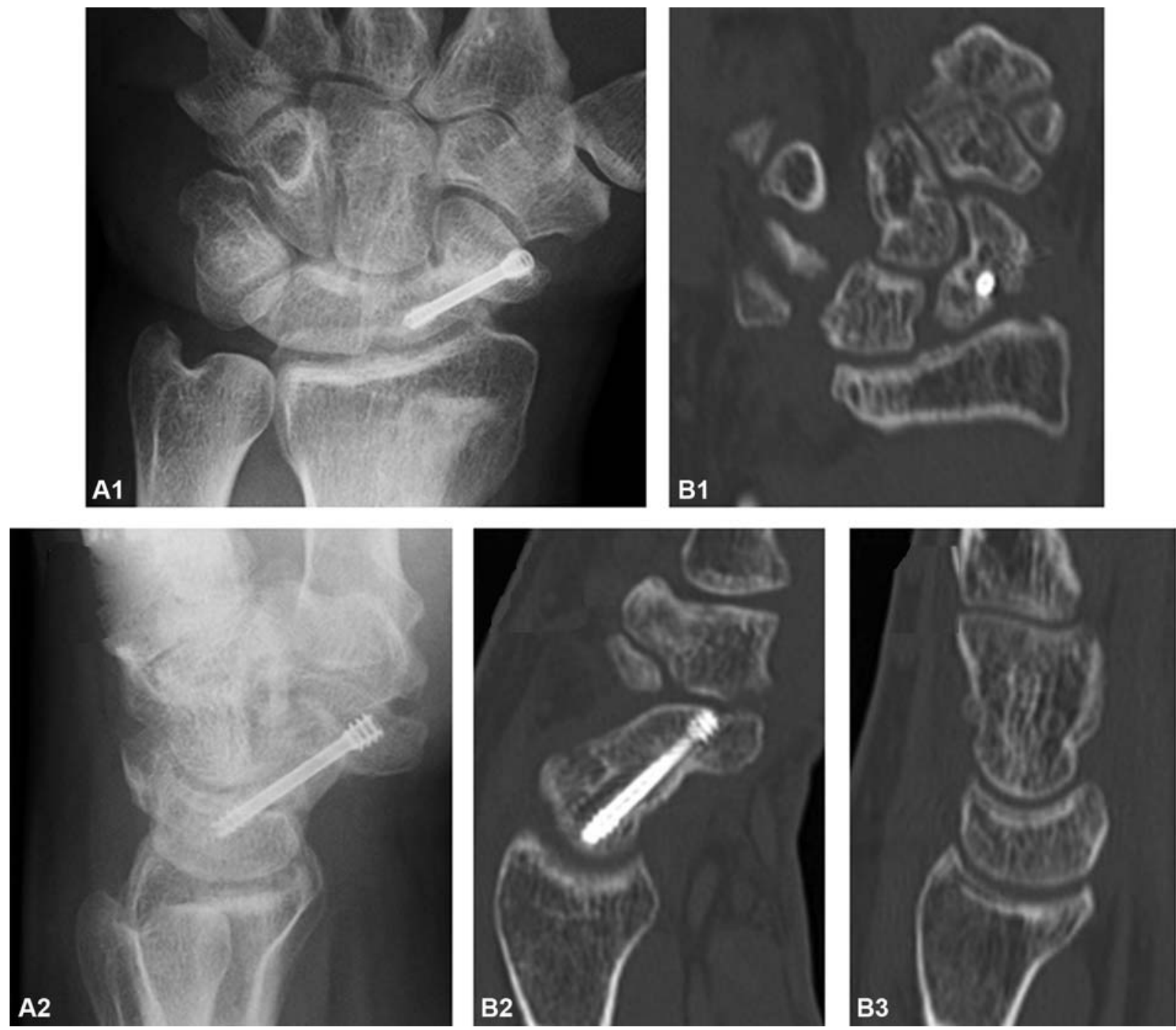

Fig.4 Postoperative images. (A1) Postoperative anterolateral radiograph. (A2) Postoperative lateral radiograph. Postoperative CT scan:(B1) coronal, (B2) sagittal on the scaphoid, (B3) sagittal on the lunate.

damage. Our technique of vascularized bone grafting using a direct lateral approach solved these problems. By detaching the joint capsule from the radius styloid and cutting it, we could safely move the pedicle to insert the graft bone onto the volar side for precise humpback deformity correction using hard cortical bone, and there was no need to cut the volar capsule or the volar wrist ligament. It is also safe, because the vascular anatomy in the harvested region is well understood. $^{27}$

A radial approach for scaphoid nonunion was reported as early as 1946 by Murray ${ }^{28}$ who resected the radial styloid from the radial side and used it as a peg for bone union. Later, Cooneyet $\mathrm{al}^{14}$ and Barnard and Stubbins ${ }^{29}$ developed a modified technique for nonvascularized bone grafting using the radial approach. Alternatively, Moreno and Gupta $^{30}$ treated scaphoid nonunion with a vascularized bone graft using a dorsi radial approach, similar to our technique, but only for proximal scaphoid nonunions. In addition, the graft was not inserted on the volar side and their long-term results were not reported. ${ }^{30}$ Our technique uses a morelateral approach that allows for safe detachment of the capsule from the radial styloid based on the arterial anatomy reported by Waitayawinyu et al. ${ }^{10,26}$ The primary advantages of our technique are the preservation of pedicle tension (because the pedicle is routed along a shortcut to the scaphoid bone) and the ability to graft a large section of hard cortical bone onto the volar side. However, there were only two cases of longstanding interval from fracture of more than 10 years. Because one of the two cases failed to show bone union, we were unable to conclude that our technique is a good adaptation for longstanding scaphoid nonunion.

The indication of this technique for elderly patients (older than 65 years old) seemed to be challenging. Patient no.10 who failed to union was 68 years old and duration of nonunion was 30 years with AVN, SNAC wrist stage I, and humpback deformity. Patient no.11 who achieved bone union was 70 years old with AVN and SNAC stage I but duration of disease was only 7 months. We think application of this technique for elderly patients with risks of nonunion would be challenging and proximal low carpectomy would be a better and simple surgical option than our technique. 


\section{Limitations}

This study has several limitations. First, it is a retrospective case series and therefore not homogenous. The interval from injury to surgery ranged widely from 2 month to 30 years and wide age range with some cases of SNAC wrist. In particular, the longstanding cases of more than 10 years were only two, and this sample data are small. Second, there was no controlled study of conventional treatment of vascularized bone graft.

\section{Conclusion}

In conclusion, our technique was useful for scaphoid nonunion with humpback deformity and AVN using only one incision.

\section{Conflict of Interest \\ None declared.}

\section{References}

1 Matti H. Technik und Resultate meiner Pseudarthrosenoperation. Zbl Chir 1936;63:1442-1453

2 Russe O. Fracture of the carpal navicular. Diagnosis, nonoperative treatment, and operative treatment. J Bone Joint Surg Am 1960; 42-A:759-768

3 Fisk GR. Carpal instability and the fractured scaphoid. Ann R Coll Surg Engl 1970;46(02):63-76

4 Zaidemberg C, Siebert JW, Angrigiani C. A new vascularized bone graft for scaphoid nonunion. J Hand Surg Am 1991;16(03): 474-478

5 Makino M. Vascularized metacarpal bone graft for scaphoid nonunion and Kienbock's disease. J Reconstr 2000;6:261-267

6 Kuhlmann JN, Mimoun M, Boabighi A, Baux S. Vascularized bone graft pedicled on the volar carpal artery for non-union of the scaphoid. J Hand Surg [Br] 1987;12(02):203-210

7 Mathoulin C, Brunelli F. Further experience with the index metacarpal vascularized bone graft. J Hand Surg [Br] 1998;23 (03):311-317

8 Yuceturk A, Isiklar ZU, Tuncay C, Tandogan R. Treatment of scaphoid nonunions with a vascularized bone graft based on the first dorsal metacarpal artery. J Hand Surg [Br] 1997;22(03): 425-427

9 Chang MA, Bishop AT, Moran SL, Shin AY. The outcomes and complications of 1,2-intercompartmental supraretinacular artery pedicled vascularized bone grafting of scaphoid nonunions. J Hand Surg Am 2006;31(03):387-396

10 Waitayawinyu T, McCallister WV, Katolik LI, Schlenker JD, Trumble TE. Outcome after vascularized bone grafting of scaphoid nonunions with avascular necrosis. J Hand Surg Am 2009;34(03): 387-394

11 Tomaino MM. Preliminary lunate reduction and pinning facilitates restoration of carpal height when treating perilunate dislocation, scaphoid fracture and nonunion, and scapholunate dissociation. Am J Orthop 2004;33(03):153-154
12 Munk B, Larsen CF. Bone grafting the scaphoid nonunion: a systematic review of 147 publications including 5,246 cases of scaphoid nonunion. Acta Orthop Scand 2004;75(05):618-629

13 Pinder RM, Brkljac M, Rix L, Muir L, Brewster M. Treatment of scaphoid nonunion: a systematic review of the existing evidence. J Hand Surg Am 2015;40(09):1797-1805.e3

14 Cooney WP III, Dobyns JH, Linscheid RL. Nonunion of the scaphoid: analysis of the results from bone grafting. J Hand Surg Am 1980;5(04):343-354

15 Tambe AD, Cutler L, Murali SR, Trail IA, Stanley JK. In scaphoid non-union, does the source of graft affect outcome? Iliac crest versus distal end of radius bone graft. J Hand Surg [Br] 2006;31 (01):47-51

16 Krimmer H. Management of acute fractures and nonunions of the proximal pole of the scaphoid. J Hand Surg [Br] 2002;27(03): 245-248

17 Carrozzella JC, Stern PJ, Murdock PA. The fate of failed bone graft surgery for scaphoid nonunions. J Hand Surg Am 1989;14(05): 800-806

18 Osterman AL, Mikulics M. Scaphoid nonunion. Hand Clin 1988;4 (03):437-455

19 Green DP. The effect of avascular necrosis on Russe bone grafting for scaphoid nonunion. J Hand Surg Am 1985;10(05):597-605

20 Ribak S, Medina CE, Mattar RJr, Ulson HJ, Ulson HJ, Etchebehere M. Treatment of scaphoid nonunion with vascularised and nonvascularised dorsal bone grafting from the distal radius. Int Orthop 2010;34(05):683-688

21 Megerle K, Harenberg PS, Germann G, Hellmich S. Scaphoid morphology and clinical outcomes in scaphoid reconstructions. Injury 2012;43(03):306-310

22 Fernandez DL. Anterior bone grafting and conventional lag screw fixation to treat scaphoid nonunions. J Hand Surg Am 1990;15 (01):140-147

23 Sawaizumi T, Nanno M, Ito H. Vascularized second metacarpalbase bone graft in scaphoid non-union by the palmar approach. J Reconstr Microsurg 2003;19(02):99-106

24 Tambe AD, Cutler L, Stilwell J, Murali SR, Trail IA, Stanley JK. Scaphoid non-union: the role of vascularized grafting in recalcitrant non-unions of the scaphoid. J Hand Surg [Br] 2006;31(02): 185-190

25 Arora R, Lutz M, Zimmermann R, Krappinger D, Niederwanger C, Gabl M. Free vascularised iliac bone graft for recalcitrant avascular nonunion of the scaphoid. J Bone Joint Surg Br 2010;92(02): 224-229

26 Jones DB Jr., Bürger H, Bishop AT, Shin AY. Treatment of scaphoid waist nonunions with an avascular proximal pole and carpal collapse. Surgical technique. J Bone Joint Surg Am 2009;91 (Suppl 2):169-183

27 Waitayawinyu T, Robertson C, Chin SH, Schlenker JD, Pettrone S, Trumble TE. The detailed anatomy of the 1,2 intercompartmental supraretinacular artery for vascularized bone grafting of scaphoid nonunions. J Hand Surg Am 2008;33(02):168-174

28 Murray G. End results of bone-grafting for non-union of the carpal navicular. J Bone Joint Surg Am 1946;28(04):749-756

29 Barnard L, Stubbins SG. Styloidectomy of the radius in the surgical treatment of non-union of the carpal navicular; . a preliminary report. J Bone Joint Surg Am 1948;30A(01):98-102

30 Moreno R, Gupta A. Vascularized bone grafts for the repair of scaphoid nonunion. Atlas Hand Clin 2003;8:117-128 